\title{
Médiévales
}

Langues, Textes, Histoire

Laurence MOAL, L'Étranger en Bretagne au Moyen Âge.

Présence, attitudes, perceptions, Rennes, Presses Universitaires de Rennes, 2008, 437 p., XVI pages de planches.

\section{François Brindejonc}

\section{(2) OpenEdition}

1 Journals

\section{Édition électronique}

URL : https://journals.openedition.org/medievales/6180

DOI : 10.4000/medievales. 6180

ISSN : 1777-5892

Éditeur

Presses universitaires de Vincennes

\section{Édition imprimée}

Date de publication : 31 décembre 2010

Pagination : 199-201

ISBN : 978-2-84292-267-2

ISSN : 0751-2708

Référence électronique

François Brindejonc, « Laurence moAL, L'Étranger en Bretagne au Moyen Âge. Présence, attitudes, perceptions, Rennes, Presses Universitaires de Rennes, 2008, 437 p., xvı pages de planches. », Médiévales [En ligne], 59 | automne 2010, mis en ligne le 10 mars 2011, consulté le 22 avril 2022. URL : http://journals.openedition.org/medievales/6180 ; DOI : https://doi.org/10.4000/medievales.6180

Ce document a été généré automatiquement le 22 avril 2022.

Tous droits réservés 


\title{
Laurence MOAL, L'Étranger en Bretagne au Moyen Âge. Présence, attitudes, perceptions, Rennes, Presses Universitaires de Rennes, 2008, 437 p., XVI pages de planches.
}

\author{
François Brindejonc
}

1 Au cœur des questionnements de notre modernité sur l'altérité, l'ouvrage de Laurence Moal, issu d'une thèse soutenue en 2007, participe à un nouvel éclairage sur son acception médiévale. L'auteur développe une problématique sur ce qui fait l'étranger dans la principauté bretonne sous la dynastie des Montfort (1364-1514). L'intérêt majeur du travail de L. Moal est de s'interroger sur le statut que prend l'étranger, non pas au sein de l'État royal, mais dans un territoire princier dépendant plus ou moins de la couronne, le duché de Bretagne. Alors que le statut d'étranger est lui-même en construction par l'administration royale à la fin du Moyen Âge, qu'en est-il au sein d'un territoire qui, en théorie, dépend du roi de France mais qui, dans les faits, ressortit à un duc dont le pouvoir s'émancipe de celui du roi ? Dans la lignée des travaux de M. Jones et surtout de J. Kerhervé, qui préface l'ouvrage, la problématique primordiale de cette étude est donc celle de la construction de l'État breton, «État non national, État de fait et non État de droit » comme le résume l'auteur dans son introduction. En conséquence de cette première interrogation, l'objectif de L. Moal est aussi, en filigrane, l'élaboration d'une identité nationale bretonne. En outre, son dénombrement des étrangers passant ou vivant sur le sol breton entre 1364 et 1514 lui permet de s'interroger sur la place du duché dans l'ensemble français. Le jeu des échanges et des flux humains en fait-il une terre intégrée à l'espace français ou un espace autonome fortement relié aux grandes dynamiques de l'ouest du continent?

Dans un premier temps, l'historienne nous présente l'objet de sa recherche. Elle a traqué à travers des sources variées (chroniques bretonnes, actes et mandements de la 
chancellerie ducale, trésor des chartes, actes municipaux de Rennes et de Nantes, actes de la chancellerie anglaise) la présence des individus désignés comme étrangers au duché. Son enquête manque cependant d'une analyse plus approfondie de ce que désigne le terme estrangier entre la fin $\mathrm{du} \mathrm{XI}^{\mathrm{e}}$ et le cours du XII ${ }^{\mathrm{e}}$ siècle. Forgé à partir du latin extraneus, il désigne alors tant l'étranger que ce qui est ou doit être évité. Alors que le sentiment d'appartenance est avant tout un lien d'homme à homme - on est homme de sa lignée, de son seigneur ou de sa communauté, avant de se définir par une autorité plus lointaine - les termes de horsain et de forain, apparus entre la fin du XII et le XIII ${ }^{e}$ siècles, continuent de désigner les personnes venues du « dehors ». La notion d'«étranger » se précise et prend réellement sens avec la mise en place d'un pouvoir constitué, celui d'une administration étatique de plus en plus performante.

3 Après une mise au point sur la méthode qu'elle emploie, prosopographique et sociologique, elle examine la présence étrangère en Bretagne selon trois critères : la fonction des étrangers et la raison de leur présence sur le sol breton, leur installation éventuelle et leur réception souvent violente par la société bretonne. La difficulté du dénombrement tient en plusieurs causes: l'aspect parcellaire des sources, leur irrégularité dans la désignation d'un étranger, dans leur patronyme mais aussi dans la durée de leur présence dans le duché. Y sont inclus les sujets voisins du roi de France, auquel cas leur origine régionale est précisée, Normands, Angevins et Poitevins principalement, mais aussi gens de guerre ou marchands anglais, hanséates ou visiteurs byzantins.

4 À partir des actes administratifs ducaux, L. Moal a établi une banque de données regroupant 2603 entrées. Elle précise que l'état lacunaire de la documentation ne permet pas de dresser une liste exhaustive des étrangers présents en Bretagne durant la fin du Moyen Âge. Ce sont les Britanniques (940/2603) qui offrent les plus forts contingents. Ils sont pour la plupart gens de mer et de commerce et, fait moins surprenant, gens de guerre, surtout dans la deuxième moitié du XIV ${ }^{e}$ siècle où les suites de la guerre de succession et l'alliance ducale leur ont alloué terres et châteaux. La présence française est plus équilibrée et a tendance à s'accroître avec le temps. Gens de commerce et gens de guerre s'y répartissent dans les mêmes proportions (autour de 100). Plus complexes à analyser, les gens de guerre français apparaissent autant comme ennemis du duc que comme gens à son service, principalement sous les règnes de Jean IV (1364-1399) et de François II (1458-1489). Reflet de l'intensification et de la complexité des relations avec le voisin français, les gens de cour, les diplomates mais aussi les officiers royaux apparaissent comme les Français les plus présents dans les actes administratifs bretons (plus de 120 occurrences). Troisième communauté présente, les marchands espagnols semblent plus réguliers à fréquenter la Bretagne ; moins nombreux que les Anglais et les Français, ils n'en sont pas moins les seuls à fonder une véritable colonie à Nantes, centre du pouvoir ducal à partir du $\mathrm{Xv}^{\mathrm{e}}$ siècle. Cette régularité montre non seulement l'insertion de la péninsule bretonne dans les flux commerciaux croissants entre Europe méridionale et septentrionale, mais aussi et surtout son inscription dans des circuits économiques indépendants du royaume de France.

5 Dans une deuxième partie, L. Moal oriente son étude sur le traitement de l'étranger par le pouvoir ducal en s'interrogeant sur la présence ou non d'un cadre juridique particulier aux étrangers dans le duché. Comme dans les autres principautés territoriales, il n'existe pas en Bretagne, contrairement à la France, un droit d'aubaine 
offrant un statut aux personnes vivant sur un territoire en dehors du ban de leur seigneur. Si les progrès de l'administration ducale ont permis l'instauration d'un droit de déshérence - le duc revendique les biens d'un étranger mort sans héritier -, il entre parfois en concurrence avec celles des seigneurs locaux comme l'abbé de Quimperlé en 1420. La question de la naturalisation est plus épineuse. La collation d'une lettre de naturalité permet à celui qui la reçoit d'être considéré comme un indigène et donc de pouvoir tester selon la coutume du pays. Les lettres de naturalité apparaissent dans le royaume de France autour de 1340. À l'origine, elles ont pour but de lever les incapacités successorales qui imposent lourdement les étrangers. Elles sont assez rares en Bretagne, jusqu'en 1417. Après Azincourt, en effet, 10 à 12000 Normands fuient l'occupant anglais et se réfugient dans la péninsule. Le duc leur délivre alors trois cents lettres de grâce ou de naturalité afin qu'ils s'installent comme drapiers à Fougères. L'expérience est renouvelée en février 1422 dans les mêmes buts. Mais ces actes demeurent rares et ne deviennent importants qu'après le mariage de la duchesse Anne avec le roi Charles VIII et sont donc le fait de la chancellerie française. Les lettres de naturalité ne peuvent donc servir à montrer la mise en place d'une législation ducale spécifique aux étrangers.

Dans la troisième partie, L. Moal tente d'appréhender la réception de l'étranger par les Bretons eux-mêmes, à partir de cinq chroniques. Chapitre au croisement de l'histoire des représentations et de l'histoire culturelle, la vision de l'étranger est cependant traitée de manière trop superficielle. Les deux premières chroniques rédigées à la fin du XIV ${ }^{e}$ siècle (le Chronicon Briocense, et Le Bon Jehan et le Jeu des échecs de Guillaume de Saint-André), encore marquées par les affres de la Guerre de succession, traitent l'étranger, principalement l'Anglais et le Français, comme un guerrier venu saigner les forces vives de la péninsule. Les trois autres textes sont de la fin $d u \mathrm{xv}^{\mathrm{e}}$ siècle: les Grandes chroniques de Bretagne d'Alain Bouchart, la Chronique de Bretagne de Jean de Saint-Paul et l'Histoire de Bretagne de Pierre Le Baud. Elles font œuvres de propagande en exaltant les valeurs de la nation bretonne, l'État ducal étant en train de disparaître, l'étranger y est donc souvent dépeint conquérant et mauvais. Cette vision des élites de cour n'est qu'une recomposition partiale et non le reflet d'une perception réelle de l'étranger. Cette troisième partie apparaît donc fort parcellaire: impossible de percevoir comment les Bretons anonymes se représentent réellement l'étranger. Peu de traitement non plus de la manière dont se positionne la noblesse bretonne : pendant cent cinquante ans, celle-ci ne cesse d'osciller entre roi et duc, son regard sur ce qui fait l'étranger n'a donc pu qu'évoluer durant la période et varier par rapport à celle du duc.

7 Positionnée à la croisée de l'histoire politique et de l'histoire sociale, la principale critique qui pourrait être adressée à ce livre est de traiter la question de l'étranger de manière incomplète, notamment en renonçant à une approche d'anthropologie historique. Aurait ainsi été montrée avec plus de clarté la lente élaboration de cette notion au sein d'un territoire indépendant de fait mais qui ne s'est jamais réellement constitué en nation. Relativement réduite, la place de l'étranger ne se distingue vraiment au cours du siècle et demi concerné que lorsqu'elle s'inscrit dans la durée. Mais l'orientation de la problématique principalement autour de l'élaboration d'un État breton, voire d'une nation bretonne, se fait à l'aune de son jugement de l'étranger plus qu'à celle de l'étranger lui-même. Cependant, L. Moal montre bien que la présence d'étrangers n'engendre pas dans le duché le même degré d'élaboration juridique que dans le royaume, malgré la politique d'émancipation menée et encouragée par le duc 
Jean IV (1365-1399) et ses successeurs, qui procédait non seulement d'un désir politique mais aussi d'une réalité socio-économique. 